\title{
Knocking the doors of residency
}

Gupta P

MS Resident, Department of Ear, Nose and Throat Kathmandu Medical College Teaching Hospital, Kathmandu, Nepal

$\mathrm{B}$ eing a post-graduate student to complete his/her residency and that too in his/her desired subject is the dream of almost all of us and so was mine.

For me, it was like being born in Kathmandu Medical College (KMC) and also brought up here. I started MBBS almost immediately after completing grade 12 and that too without the aid of any so called preparatory classes. I completed MBBS with lots of hard work as well as smart work. Internship flew off in a similar fashion. Then, was the time to do a job. I was $100 \%$ sure that I will not go abroad for my residency. I wanted to do a job in a subject of my interest and also not forgetting the fact that I would even get enough time to study where I work.

Four and half years of MBBS at KMC was filled with nightmares of exams almost every week. Many of us could not overcome the stress and I had seen many of my friends during MBBS taking Alprazolam for "so called" exam fears. Alprazolam used to relieve their stress and relax their mind. But they were unaware of the fact that this so called wonder medicine was making them dependent on it. Instead I think they should have shared their stress and exam fears with their family and close friends instead of being dependent on Alprazolam.

I had interest in two subjects: Psychiatry and Otorhinolaryngology (ENT). I used to wonder how a small mind can have so many psychiatric disorders. So, I chose Psychiatry to work as a medical officer. Working in Psychiatry was fun. I got a chance to work with all the renowned doctors who taught me a lot. In between, I appeared in various post-graduate examinations in duration of about nine months after completing my internship and got many chances to study but not in a subject which I desired. Then, was the turn for Kathmandu University examinations.

Otorhinolaryngology was a subject of my interest since I entered MBBS. Though our curriculum has classified it as a subject under "MINOR", for me it was a major subject.

Address for correspondence
Dr. Priyanka Gupta
$1^{\text {st }}$ year MS resident
Department of Ear, Nose and Throat
Kathmandu Medical College Teaching Hospital, Kathmandu, Nepal
Email: peekugupta@gmail.com

Though it is a subject with complex anatomy as many structures are situated in a relatively small space, I had interest in it. ENT is itself a subject of super speciality. I worked in Psychiatry for almost a year and had enough exposure in it I thought. I wanted to get exposure as well as wanted to be a renowned Otorhinolaryngologist. I took Kathmandu University (KU) entrance exam with almost no hope. I saw my seniors giving the KU exams with enough confidence that they will qualify the exams. I even had examples of so many of my seniors who were sure that they will get the subject of their choice wherever they want but in vain.

I got a call for interview after qualifying the written exams. The gap between the interview and the written results was filled with a fear of not getting a sponsor letter as many of my friends from other colleges. The final results knocked the doors of residency for me.

Though I got a chance to work as a post-graduate resident in the same place where I studied and worked, it was still a different feeling when I entered as a resident in ENT ward on the first day. I had all the familiar faces surrounding me with a new and unfamiliar face as my colleague. It was a mixed feeling with happiness, anxiety and a lot of questions in my mind. I completed that first day with a lot of memories. Though I walked the same passage of KMC many times a day since I entered medical field, it was a totally new and different experience working as a resident on the same passage on the first day. I wondered how my colleague felt who was totally new to KMC and KMC was new to her as well.

Having completed the first day, I had just these lines in my mind:

THE WOODS ARE LOVELY DARK AND DEEP

BUT I HAVE PROMISES TO KEEP

AND MILES TO GO BEFORE I SLEEP

AND MILES TO GO BEFORE I SLEEP!!!!

I would just like to tell my juniors that study in a subject of your interest and please do not believe in all the rumours of others' experience of various postgraduate examinations as many of these rumours are just to dishearten you and to step you back.

Give your best for what you want and you will get it!!!!! 
